\title{
Mapping hotspots and emerging trends of business model innovation under networking in Internet of Things
}

\author{
Yuran $\operatorname{Jin}^{1,2^{*}}$ and Shoufeng $\mathrm{Ji}^{2}$
}

\begin{abstract}
Networking in Internet of Things (IOT) has had an immeasurable impact on the existing business models. In this context, exploring the hotspots and trends of business model innovation has become particularly necessary. For the topic literature over the past 20 years retrieved from Science Citation Index and Social Sciences Citation Index databases, scientometrics with information visualization technology was used to carry on the knowledge mapping with the following indicator: the co-cited reference networks, reference bursts, keyword bursts, and keyword co-occurrence networks. The results show (1) "e-commerce," "open source," "performance," "entrepreneurship," etc. are the main hotpots, and "value creation," "open innovation," "small business," "networks," etc. are the new hotpots; (2) the trends of hotspots transited from early "information technology" to later "self-service," "mass customization," and "biotechnology" and to present "cloud manufacturing," "telemedicine," "climate change," and "sustainable development,". etc.; (3) "intelligent robot," "3D printing," and the methodology of business mode innovation may be the future hotspots. This is the first paper visualizing the hotspots and emerging trends of business model innovation specially through scientometrics from a global perspective.
\end{abstract}

Keywords: Business model innovation, Visualization, Networking, Internet of things, Scientometrics

\section{Introduction}

The IoT is a large network which realizes machine-tomachine communication that integrates the current devices, such as RFID devices, sensors, and other equipment and services. IoT extends the form of interaction between people to the interaction between people and things as well as things and things and then establishes a new ecological environment $[1,2]$. Actually, the IoT is a kind of special result of networking. Networking has had an immeasurable impact on the existing business models. The networking of social networks and the networking of information are promoting the transformation of traditional business models [3, 4]. Networked social network has changed the organizational structure and operation strategy of traditional business models [5-9]. Information networking, especially the wireless

\footnotetext{
* Correspondence: jinyuran@163.com

'School of Business Administration, University of Science and Technology Liaoning, Anshan 114051, China

${ }^{2}$ School of Business Administration, Northeastern University, Shenyang 110167, China
}

communication network, has changed the information flow and decision-making mechanism of traditional business models [10-12]. In addition, in view of the growing value of the network $[13,14]$, enterprises have seen the way to promote the development of the enterprise by optimizing the value network. Therefore, networking in IoT also has the characteristics that affect the existing business models. In this context, exploring the hotspots and trends of business model innovation has become particularly meaningful for the development of IoT and related industries.

Drucker Peter, the father of modern management, argues that "Today's competition between enterprises is not the competition between products, but the competition between business models" [15]. Under the high attention of all circles of society, the relevant researches about business model innovation have rapidly developed. Some scholars studied dynamic problems of the business model innovation. For example, Afuah and L. Tucci [16] thought business model is a system composed of three factors: the different component parts, the connection 
relations between parts, and the dynamic mechanism of system. Osterwalder [17] believed that business model innovation can be driven not only by the supply chain but also by the demand chain in the value system. Zeng and Song [18] summed up the driving forces of business model innovation, namely the marketization of new technology, market environment pressure, and the market opportunity to promote development. There are some other scholars studying the paths of business model innovation. For example, Mitchell and Coles [19] proposed three necessary conditions for business model innovation. Osterwalder et al. [20] put forward three steps of business model innovation. In addition, some scholars focus on the business model innovation method. These methods include SWOT analysis, the long tail theory, business model analysis model, value chain analysis, value stream analysis, value net analysis, activity-based management, process management and analysis tools, business model elements figure, reference method, correlation analysis method, method of key factors, value innovation, and Theory of Inventive Problem Solving [21, 22]. What is more, a few scholars have carried out the research on the trend of business model innovation. Zhao [23] studied the discipline, country, and knowledge base of business model innovation literatures and used keywords to analyze the development trend of business model innovation. This research provides a useful reference for this paper. However, after summarizing the previous research, we find that it is still lack of systematic research on "hotspots and their evolution trends of business model innovation," which is just the focus of the business model innovation, especially in IoT. Therefore, we will visualize business model innovation in this paper to reveal the research hotspot and development trend of business model innovation in different historical periods. The paper can boost the development of business model innovation theory and offer guidance and reference for the enterprises' business model innovation.

The research topics around business model innovation are also varied under networking in IoT. Therefore, we have carried out a preliminary investigation. We used the Lingo clustering method provided by Carrot $^{2}$ (http:// project.carrot2.org) to cluster the topic "business model innovation." The visualization generated by Lingo called Foam Tree in Carrot $^{2}$ is shown in Fig. 1. The results show that "open innovation," "innovation management," "service innovation," "enterprise modelling," and "product innovation" are the central topics in business model innovation. Through this survey, we have already had a preliminary research foundation about business model innovation.

The remainder of the paper is organized as follows: in Section 2, the authors describe the research tools and research methods and explain the data sources and structure. The hotspots and trends of business model innovation of core dataset are analyzed, and the comprehensive analysis based on extended dataset are explored in Section 3. Conclusions and discussion about future work are presented in Section 4.

\section{Methodology}

\subsection{Scientometric analysis by information visualization} technology

In recent years, with the rapid growth of the scientific literature and the development of network technology,

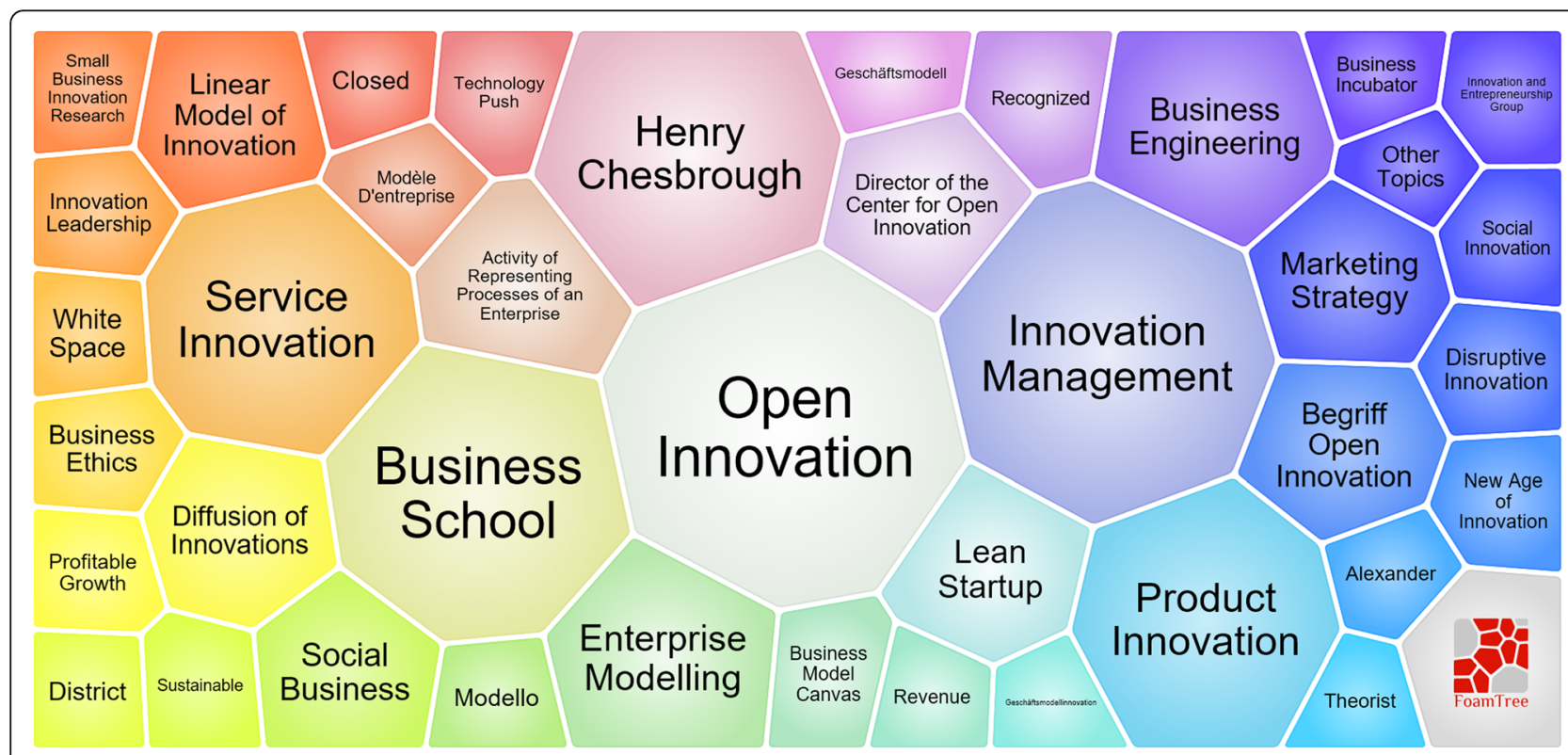

Fig. 1 A preliminary survey on the topics of business model innovation 
the large scale document processing software and data visualization technology can be used to deal with massive scientific literature data. With the help of information visualization technology, scholars can more easily observe, browse and understand the information, and find the rules and patterns hidden in the data. Information visualization technology is the theory, methods, and techniques using computer graphics and image processing technology to convert data into graphics or images displayed on the screen [24]. Among them, the CiteSpace series application software based on Java platform developed by Professor Chaomei Chen from Dexrel University in the USA is a new generation of information visualization technology, which is suitable for multiple, dynamic, and complex network analysis and has become a new method of scientific metrology [25]. CiteSpace can reveal a citation network map about the evolution of a knowledge field. The basic knowledge of node literature and the co-citation cluster characterization can be marked automatically on the map. In CiteSpace, a field of scientific knowledge map can be reflected through a variety of different types of network. It is designed to synthesize and visualize a time series of individual networks extracted from each year's publications. The resultant network can be divided into clusters. The size of a cluster is decided by the number of its members, which reflect the degree of hotspots. Clusters with the late average publication year can reflect the emerging trends in a certain field [26]. For literature co-citation network and keyword co-occurrence network, clustering represents the aggregation of similar network nodes including cited literature and keywords. The size of node represents the cited frequency of literature or the occurrence frequency of keywords. The color line represents the time of first co-citation literature or co-occurrence keyword. According to the cluster size and the average time of publication, we can judge a hot topic in the field and its time trends. In addition, the burst detection based on Kleinberg's algorithm on the cited literature and keywords can show the hotspots and their evolution process of a field during different time period. A burst begins usually in a short period of time like a single year, but it can also last for multiple years, which provides the evidence that the publication evidently has attracted an extraordinary degree of attention from its scientific community. The cited literature cited unusually frequently, and the occurring keywords with the abnormal prominent frequency are called burst literature and burst keywords individually $[27,28]$.

In addition, VOSviewer owns text mining functionality that can be used to construct and visualize bibliometric networks of important terms extracted from a body of scientific literature presented in various different ways. Through its co-occurrence keyword map, research hotspots and trends in a certain field can be more clearly showed $[29,30]$.

\subsection{Data collection}

In order to obtain more comprehensive literature data of basic science and social science research, the databases Science Citation Index (SCI) and Social Sciences Citation Index (SSCI) from Web of Science are used as the data retrieval sources. The advanced search mode is used, and the search structure is set to TS= ("business model" OR "business mode" OR "commercial model" OR "commercial mode") AND TS= (innovate OR innovati*). It is because that the earliest literature on business model innovation is 1997 in SCI and SSCI databases that the time range used to collect data is set to 1997-2016 in this paper. In addition, in order to improve the quality of analysis, we only select two types of literature, Reviews and Articles, as the data source, and then refined the retrieval results. The retrieved data is divided into the core dataset and the extended dataset. Among them, the dataset collected directly by subject search is called the core dataset, and the extended dataset is a larger dataset which is obtained after clicking the citation report of Web of Science. The retrieval results are that the core dataset includes 602 results and the extended dataset includes 4544 result (the search time is December 30, 2016). In this study, we carry out the related research with the core data set firstly and then conduct further research with the complete dataset integrating the two datasets.

\section{Results and discussion}

\subsection{Hotspots and trends based on co-cited references of the core dataset}

The analysis result from CiteSpaceIII shows the 602 literatures in the core dataset produced a total of 1510 nodes, 3461 connections, and 32 clustering from 1997 to 2016. The generated top 100 literature co-citation network knowledge map based on TFIDF algorithm [31, 32] is shown in Fig. 2. Solid borders of the figure show the distribution of main clusters of business model innovation, and the different colors of the lines reflect the co-citation time of literature. The whole knowledge map reveals the knowledge structure of clusters and the spatial and temporal trends of the hotspots of business model innovation.

The first 10 clusters of the core dataset based on the different algorithms are shown in Table 1 . The names of cluster labels are listed respectively according to the three different extraction algorithms in CiteSpace, namely term frequency-inverse document frequency (TFIDF), log-likelihood ratio (LLR), and mutual information (MI). Among them, the clustering tags generated by TFIDF are more consistent with the actual situation of 


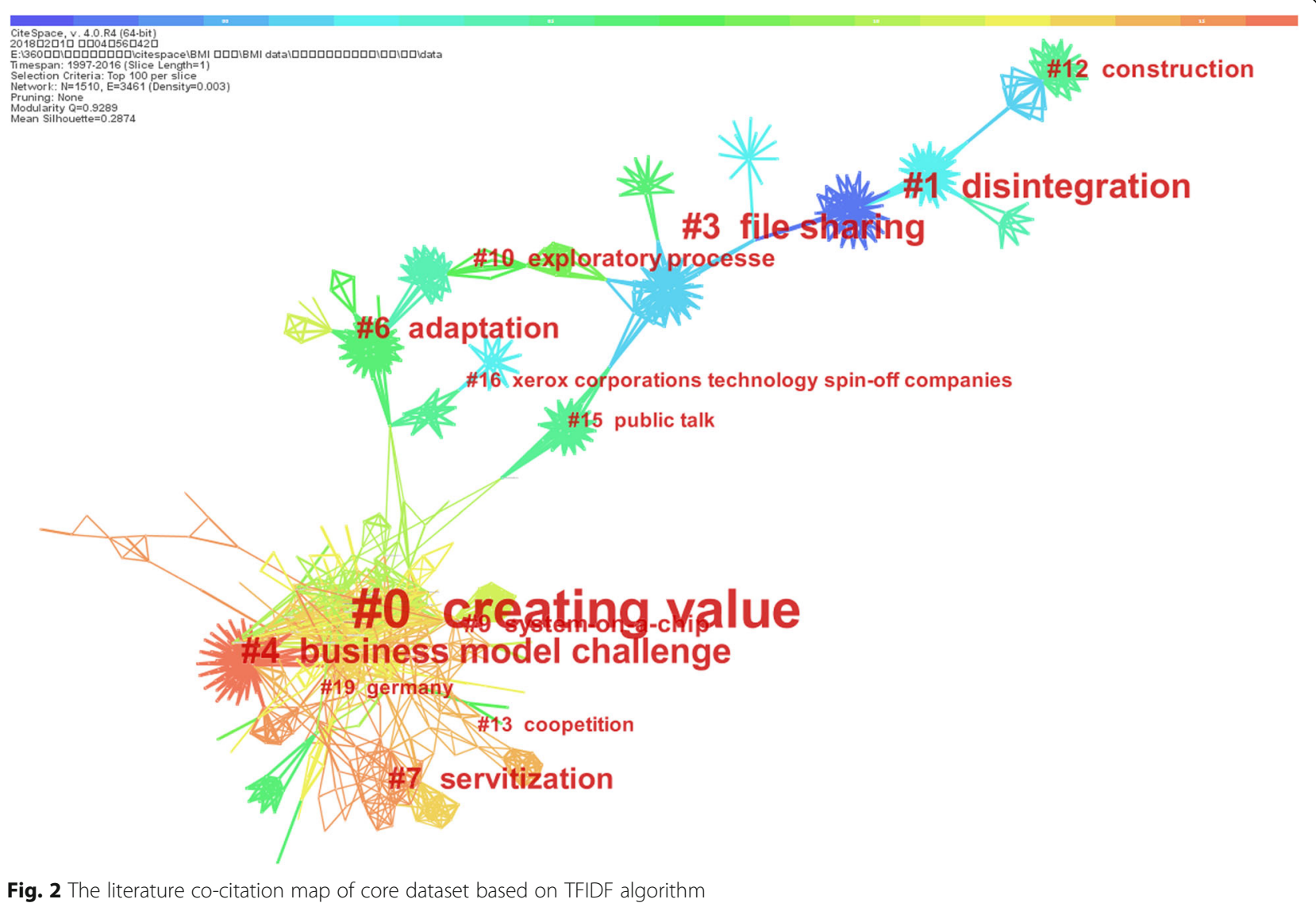

the research on the whole, and only individual clustering tags generated by LLR or MI are more representative than by TFIDF (as the words in italics shown in Table 1). The analysis result shows that "creating value," "disintegration," "open source software," and "e-business" are the four largest clusters, which embodies the hot degree of business model innovation research. Especially, "value creating" is the largest cluster, reflecting its important position in the field of business model innovation research. On the other hand, it is because the indicator "average year of publications" can reflect the average publication year of the literature in a cluster, which means the later the average year of a cluster is, the more advanced the thesis of the cluster is, that "business

Table 1 TOP 10 clusters of core dataset

\begin{tabular}{|c|c|c|c|c|c|c|}
\hline \multirow[t]{2}{*}{ Cluster } & \multirow[t]{2}{*}{ Size } & \multirow[t]{2}{*}{ Silhouette } & \multicolumn{3}{|l|}{ Label $^{a}$} & \multirow{2}{*}{$\begin{array}{l}\text { Aver. year } \\
\text { of publications }\end{array}$} \\
\hline & & & TFIDF & LLR & $\mathrm{Ml}$ & \\
\hline 0 & 127 & 0.772 & Creating value & Business model innovation & Innovation & 2007 \\
\hline 1 & 63 & 0.979 & Disintegration & Differentiability & Product development & 1997 \\
\hline 2 & 63 & 1 & State & State & Open source software & 2002 \\
\hline 3 & 57 & 0.98 & File sharing & e-business & Strategic innovation & 1998 \\
\hline 4 & 52 & 0.914 & Business model challenge & Business model challenge & Sensing business model & 2011 \\
\hline 5 & 49 & 1 & Innovative capability & New economy & - & 2000 \\
\hline 6 & 41 & 0.967 & Adaptation & Adaptation & Innovation type & 2001 \\
\hline 7 & 40 & 0.854 & Servitization & Service business model innovation & Open innovation & 2009 \\
\hline 8 & 35 & 1 & Agile enterprise & Technology management issue & - & 1993 \\
\hline 9 & 32 & 0.911 & System-on-a-chip & Design foundry & Idea generation & 2007 \\
\hline
\end{tabular}

TFIDF term frequency-inverse document frequency, LLR log-likelihood ratio, MI mutual information 
model challenge (2011)," "open innovation (2009)," and "creating value (2007)" are the research frontiers on business model innovation in recent years.

In order to analyze the research topics of hotspot clusters deeply, "creating value" and "business model challenge" are selected for detailed analysis.

\subsection{1 (1) The biggest hotspot-"creating value"}

Clustering \#0 is named "creating value" by the TFIDF algorithm and "business model innovation" by the LLR algorithm. The cluster contains the same literature though the extracted themes are different. So there is no influence on the analysis of the literature. It is because business model innovation can be reflected more deeply by creating value that we choose "creating value" as the cluster label. As the largest cluster, \#0 cluster contains 127 papers. The average year of publications is 2007 , showing that the research results are the leading edge, and the silhouette score 0.773 indicates it has a better clustering quality. The content of the literature is related to the value creation or business model innovation in this cluster. Among them, there are some scholars studying the relationship between value creation and business model. For example, Svejenova et al. [33] put forward the personal business model, believing that the creation, acquisition, and sharing value can affect the development of business model directly. Wirtz et al. [34] analyzed the four types of Internet business model and Web 2.0 trends, presenting the main features of business model are creation and acquisition value, and integrating Web 2.0 into the business model can create better value; there are scholars distinguishing the business model from the perspective of value creation. For example, Sanchez and Ricart [35] identified the isolated business models and the interactive business models from the perspective of value creation after analyzing the data of multiple cases and the strategy of the low-income market. They think the isolated business models use existing opportunities to enter new markets and the interactive business models need to integrate internal resources to create opportunities, and some scholars describe the importance of creating value in the business model. On the basis of theoretical construction and case study, Wu et al. [36] found that the proper value proposition can attract more customers by business model, which is conducive to the better operation of business model, and other scholars study how to carry out the business model innovation with creating value. Yunus et al. [37] proposed that business model innovation can be done through the new value propositions.

\subsection{2 (2) The emerging hotspot-" "business model challenge"}

Business model challenge is the fifth cluster (\#4), including 52 articles. The silhouette score is 0.914 , which indicates that the quality of cluster is high. The average publication year 2011 is the latest at the top 10 clustering, which shows the cluster topic is cutting-edge. The literature in cluster study mainly the challenges and obstacles faced by the business models in different fields. Based on a large number of case studies, Karakaya et al. [38] explored the business model challenges faced by a solar company in a small German town, combining with the local situation. After analyzing the evolution and obstacles of the four different types of business models during the period of 2006-2010 in electric vehicle enterprises, Bohnsack et al. [39] put forward that the environmental protection technologies are helpful to create economic value with business models, and the existing electric vehicles will be gradually turned to multipurpose vehicles with the passage of time. Christensen et al. [40] believed that the business model innovation of the renewable energy system needs the support of creating value, value capture, and technology innovation in the theoretical level, and there are still some challenges in terms of policy support and promotion in practice. Ernkvist [41] put up the continuous introduction of technology innovation, and the new business model can gradually enhance the status of electronic options trading in the financial sector. The main challenges in the process are the cumbersome and limit of regulatory process. Hermann et al. [42] developed a conceptual framework to demonstrate the application of the business model of product service systems in the maritime industry and researched the business model challenges of ballast water treatment system with the case of the Danish Maritime Industry.

\subsection{Hotpots and trends based on burst literature of core dataset}

The dynamic characteristic of a topic can be reflected by the substantial increase of citation times of literature. These literatures are referred to as burst literature, which indicate the hotspots the scientific community is being studied [43]. Figure 3 generated by CiteSpace shows the local landscape of burst literature of business model innovation. The top 8 literatures with the strongest burst in the same period from 1997 to 2016 are shown in Table 2. The start year and end year in the table reflect the trends of different hotspots based on the time. The burst intensity (strength) reflects the concern degree of the hot literature.

The first paper [44] was published on Strategic Management Journal in 2001. The paper burst from 2005 to 2009, which is the earliest burst literature. The authors 


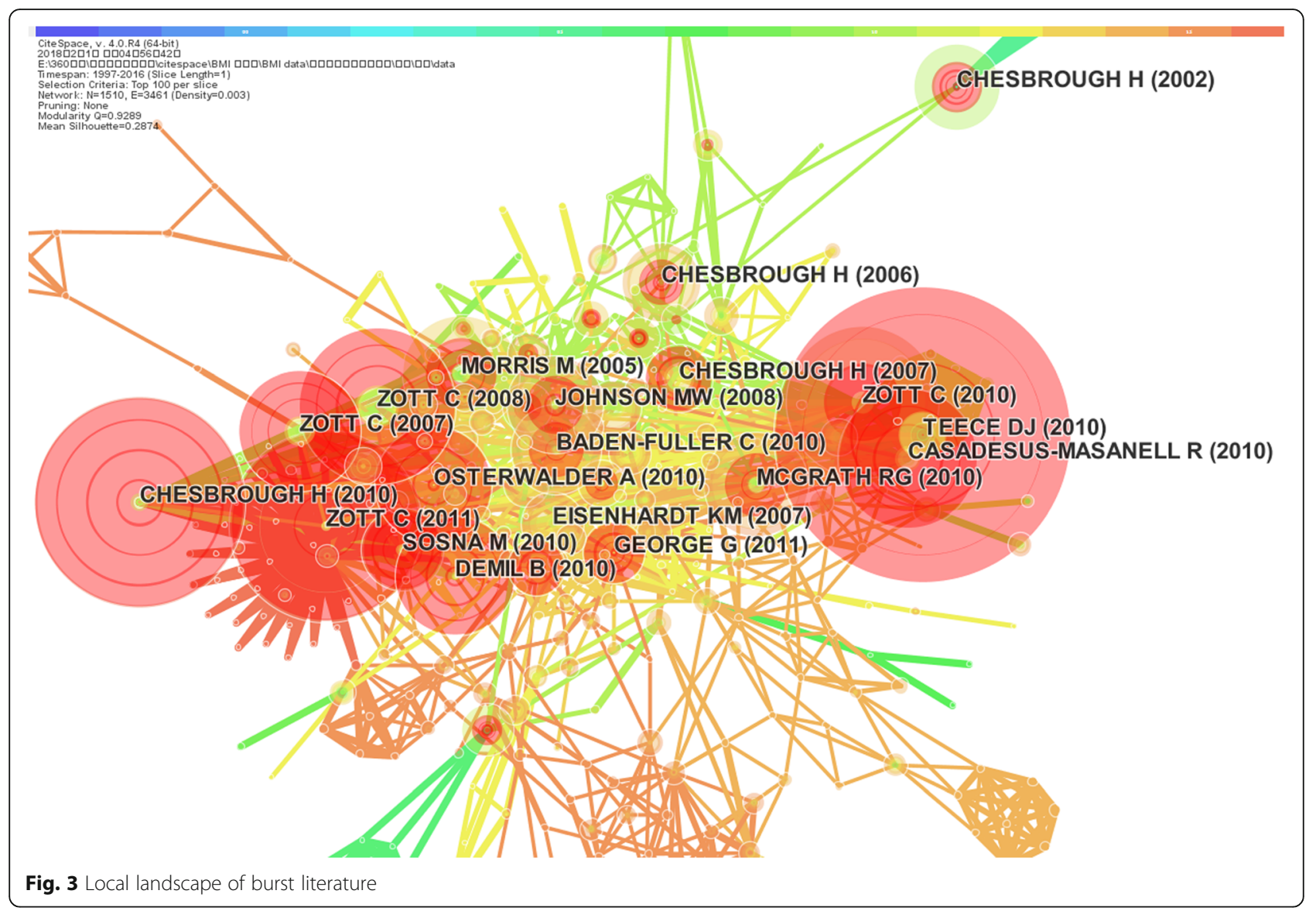

Amit $\mathrm{R}$ and Christoph $\mathrm{Z}$ developed a value creation sources model, thinking that the value creation potential of electronic business enterprise are determined by the efficiency, the complementarity, the locking, and novelty through comparing with the business models of 59 ecommerce enterprises from the USA and Europe. Obviously, the value creation of e-business enterprises is one of the hotspots in the study of business model innovation. The second paper [45] bursts from 2006 to 2010. Its bursting strength reached 15.4612, ranked in the top second so as to be an extremely important literature in the research field of business model innovation. The paper was published in Industrial \& Corporate Change journals in 2002. Chesbrough $\mathrm{H}$ and Rosenbloom RS believed that the potential value of technology can be mined through business model. Taking Xerox Co as an example, they improved the business model of this company through analyzing the potential value of technology in different business model. The third paper [46] identified two different business models that are relevant to the research firms and the companies focusing on niche markets and defined the

Table 2 Top 8 literatures with the strongest burst in the same period (1997-2016)

\begin{tabular}{llll}
\hline References & \multicolumn{1}{l}{ Citation burst } & Begin \\
\cline { 2 - 4 } & Strength & 2005 \\
AMIT R, 2001, STRATEGIC MANAGE J, V22, P493 & 6.287 & 2006 \\
MANESBOUGH H, 2002, IND CORP CHANGE, V11, P529 & 15.4612 & 2007 & 2009 \\
MAGRETTA J, 2002, HARVARD BUS REV, V80, P86 & 3.5058 & 2008 \\
CHESBROUGH H, 2006, OPEN BUSINESS MODELS, V, P & 6.0369 & 2009 \\
MORRIS M, 2005, J BUS RES, V58, P726 & 4.4463 & 2011 \\
CHESBROUGH H, 2010, LONG RANGE PLANN, V43, P354 & 10.7677 & 2012 & 2011 \\
TEECE DJ, 2010, LONG RANGE PLANN, V43, P172 & 9.2808 & 2013 \\
\hline
\end{tabular}


development trajectory and the essence of each business model by analyzing 60 French Biotechnology SME. The fourth paper published by Magretta [47] elaborated the concept and connotation of business model, believing that a good business model is a vital part of business success, and the business model can improve the business strategy. The fifth literature [48] is a monograph published in 2006 by Harvard Business School entitled "Open Business How Thrive to in the New Innovation Landscape." The author believed that the modern business leaders must open their horizons and fully share the external intellectual property rights by adopting "open and innovative" business model. The author also proposed a diagnostic method for business model, put forward the concept of "innovation intermediary" for the first time, and pointed out the road map linking innovation and intellectual property protection. The sixth paper was published by Morris et al. [49]. The burst intensity of the paper reached 10.7677. Six constituent elements of business model were proposed, and the application of the three kinds of business models was listed in this paper. The paper was published earlier, but 6 years later in 2011, it just began to burst, which reflects this paper has been recognized and valued by more scholars in recent years. Without doubt, it is a very important hot literature in the field of business model innovation. Both the seventh paper [50] and the eighth paper [51] were published in 2010 and burst till now, which make them be the most emerging research hotspots. Article 7 is a new research result of Chesbrough $\mathrm{H}$ after the above literatures 2 and 5 . The author pointed out that the competitiveness of enterprises could not be fully promoted by increasing investment and exploring new technology rather than conducting business model innovation. The author also believed the main obstacles to the current business model innovation are the conflict between the existing assets and business models. Article 8 bursts from 2013, and its burst strengthens up to 16 . 6056 in a short period of 3 years, which has make it become the one bursting fastest and concerned highest. The paper entitled "Business models, business strategy, and innovation" was published on Long Range Planning in 2010. The author DJ Teece designed a specific business model by using the value creation mechanism, thinking the nature of the business model is the way to provide value to customers and to guide customers to pay the value. This research has become a classic enterprise theory which links the business model with the economic theory of business strategy, innovation management, and so on.

\subsection{Hotpots and trends based on keyword co-occurrence network of the core data}

Through the function of keyword co-occurrence network in VOSviewer, the research hotspots and emerging trends of a domain can be revealed [52, 53]. After 602 citing literature records were imported into VOSviewer, "Co-occurrence" was selected as the analysis type, "Unit of analysis" was set to "All keywords" indicator, and the threshold was set to 5, a keyword co-occurrence network map based on 500 keywords with the strongest total link strength was generated as shown in Fig. 4. In the figure, the keyword nodes in the map represent the hotspot topics extracted from numerous keywords that appeared many times together. We can identify the research hotspots by the size of keywords and the emerging trends by the color of keywords. The color of these keywords matches the time legend below the network map. The size of these keywords is determined by the co-occurrence frequency. As shown in Fig. 4, "performance," "strategy," "entrepreneurship," "design," "alliance," "product development," "strategic innovation," "market orientation," and "capabilities" are the research hotspots with a high co-occurrence frequency in recent years. In addition, "open innovation," "product innovation," "service innovation," "renewable energy," "Internet," and "networks" are the emerging trends in business model innovation research.

\subsection{Hotspots and trends based on co-cited references of extended dataset}

In order to carry on a more comprehensive exploration on the hotspots and trends of business model innovation, we construct a larger dataset integrating the core set and the extended set. The extended dataset includes 5146 results. Figure 5 is a knowledge map of the 400 most cited literature in 1997-2016. In the visual network, every node represents a reference, the node size depends on the number of citations, the node with a red circle shows there is a burst literature in the region, and the lines between nodes represent co-citation connection. The connection colors represent co-citation year, for example, blue represents the earliest connection, and orange represents the most recently established connection.

The new dataset is used by CiteSpaceIII to cluster the cited literatures. Table 3 summarizes the largest 10 clusters. The silhouette of these clusters is relatively large, showing the good clustering quality. As can be seen from the table, the research hotspots of business model innovation include open source, performance-based contracting, differentiability, trust, small business, and other fields. Among them, small businesses (2011), solar energy enterprises (2009), open source (2007), and performance contract (2007) 

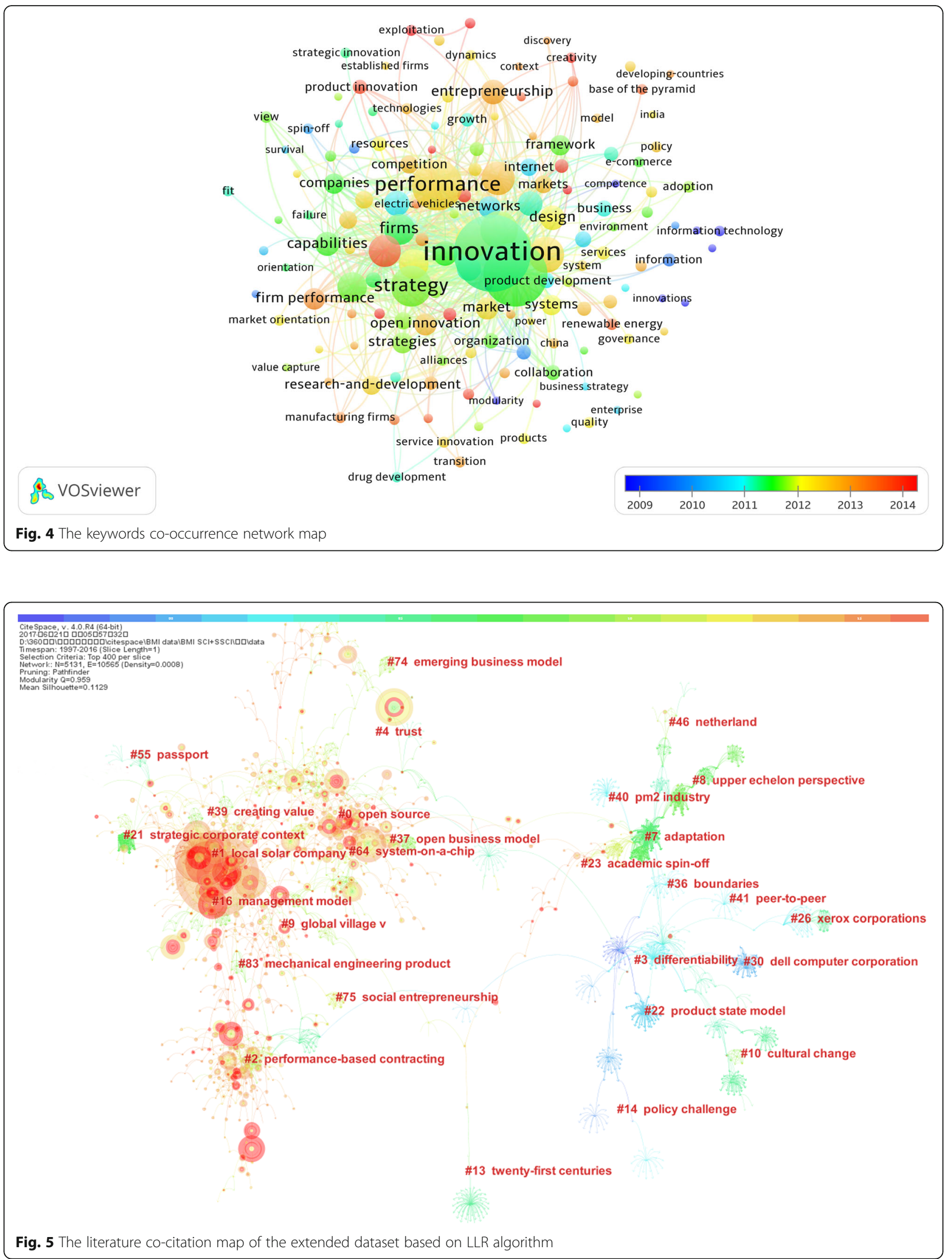
Table 3 TOP 10 clusters of extended dataset

\begin{tabular}{lllll}
\hline Cluster & Size & Silhouette & Label (TFIDF) & Aver. year of publications \\
\hline 0 & 237 & 0.889 & Open source & 2007 \\
1 & 209 & 0.894 & Local solar company & 2009 \\
2 & 192 & 0.978 & Performance-based contracting & 2007 \\
3 & 133 & 0.97 & Differentiability & 1998 \\
4 & 122 & 0.989 & Trust & 2005 \\
5 & 93 & 1 & Small business & 2011 \\
6 & 87 & 1 & Business use & 1997 \\
7 & 77 & 0.973 & Adaptation & 2001 \\
8 & 73 & 0.983 & Upper echelon perspective & 2002 \\
9 & 69 & 0.925 & Global village v & 2007
\end{tabular}

have a relatively late average year of publication, which shows these areas are emerging hotspots in recent years. We take the largest cluster and the most emerging cluster as the representative of the further analysis in the following.

\subsection{1 (1) The most popular hotspot-"open source"}

Open source is the largest cluster composed of 237 literatures with a high silhouette. Open source can be summarized as open business model. From a business point of view, open source implies that more companies need to shift to a personalized enterprise and to achieve all the benefits it promised [48]. Table 4 shows the five most cited articles in the "open source" cluster. The research content of these literatures are the hotspots of "open source". There are two articles published by Chesbrough $\mathrm{H}$ among them. The first [48] is cited with the largest number of times, even up to 72 , focusing on the "open innovation" of the business model just as the above analysis in the core dataset. The second, a monograph called "Open Innovation: Researching a New Paradigm" [54], was published by University of Cambridge Press in 2006. Thus, Chesbrough $\mathrm{H}$ is an important expert in the open innovation research of business model. Since these five papers were all published in 2006, it is seen that "open source" in 2006 is highly concerned, which has become a hot spot for business model innovation.

Table 4 The five most cited papers in the "open source" cluster

\begin{tabular}{ll}
\hline Citation times & References \\
\hline 72 & Chesbrough H (2006) \\
64 & Laursen K (2006) \\
60 & Hair JF (2006) \\
59 & Bonaccorsi A (2006) \\
52 & Chesbrough H (2006) \\
\hline
\end{tabular}

\subsection{2 (2) The most cutting-edge hotspot - "small business"}

The cluster small business contains a total of 93 literatures. Its average year of publication is 2011 so as to be the youngest cluster, which reflects more and more people begin to pay attention to the business model innovation of small enterprises in recent years. Table 5 lists the five most cited references in this cluster. These literatures discussed the hotspots of "business model innovation of small enterprise." For example, Hotho and Champion [55] studied the challenges of business model innovation in the small business model of the creative industries. Huarng [56] researched the process innovation and value creation of non-profitable small- and medium-sized enterprises. Data shows that the five papers were all published in 2011, which reflects the business model innovation of small enterprise was a hot research focus in 2011.

\subsection{Hotspots and trends based on burst keywords of extended dataset}

Burst keywords can be used as indicators to identify emerging trends [43]. Figure 6 shows the top 30 burst keywords according to burst begin year on business model innovation in 1997-2016. We can get the following information from the data analysis. At the end of twentieth century, the keywords "information technology" began to burst. In the first 10 years of twenty-first century, "internet," "e-commerce," "resource based view," "self-service," "mass customization," and "biotechnology" appeared suddenly as keywords. Since 2010, "cloud manufacturing," "cloud

Table $\mathbf{5}$ The five most cited papers in the "small business" cluster

\begin{tabular}{ll}
\hline Citation times & Literatures \\
\hline 54 & Hotho S (2011) \\
50 & Huang KH (2011) \\
48 & Goktan AB (2011) \\
39 & Naranjo-valencia (2011) \\
29 & Lee SM (2012) \\
\hline
\end{tabular}




\begin{tabular}{|c|c|c|c|c|c|}
\hline $\begin{array}{c}\text { Keywords } \\
\text { information technology }\end{array}$ & $\begin{array}{l}\text { Year } \\
1997\end{array}$ & $\begin{array}{r}\text { Strength } \\
4.2056\end{array}$ & $\begin{array}{l}\text { Begin } \\
1999\end{array}$ & $\begin{array}{l}\text { End } \\
2002\end{array}$ & $1997-2016$ \\
\hline internet & 1997 & 14.3123 & 2000 & 2007 & - \\
\hline replication & 1997 & 5.14 & 2001 & 2007 & - \\
\hline world wide web & 1997 & 4.006 & 2002 & 2008 & -_-_ \\
\hline resource based view & 1997 & 5.2239 & 2002 & 2005 & $=$ \\
\hline electronic commerce & 1997 & 6.8622 & 2002 & 2011 & 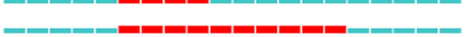 \\
\hline sustained competitive advantage & 1997 & 4.518 & 2002 & 2009 & 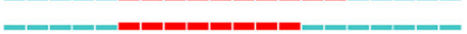 \\
\hline organizational learning & 1997 & 3.5445 & 2003 & 2009 & 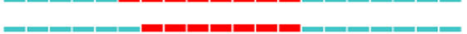 \\
\hline electronic data interchange & 1997 & 4.7305 & 2003 & 2008 & \\
\hline dynamic capability & 1997 & 5.1918 & 2003 & 2007 & ב-ב- \\
\hline information & 1997 & 3.8383 & 2003 & 2007 & - \\
\hline e mail & 1997 & 3.1037 & 2003 & 2006 & \\
\hline mass customization & 1997 & 4.1212 & 2004 & 2007 & 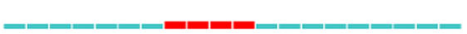 \\
\hline biotechnology & 1997 & 4.4036 & 2004 & 2009 & 드드-1 \\
\hline e business & 1997 & 12.2746 & 2004 & 2008 & \\
\hline e commerce & 1997 & 7.968 & 2004 & 2008 & - \\
\hline corporate strategy & 1997 & 3.9222 & 2004 & 2009 & 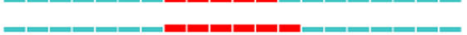 \\
\hline boundary & 1997 & 3.6396 & 2006 & 2011 & 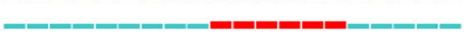 \\
\hline knowledge transfer & 1997 & 3.1822 & 2006 & 2007 & 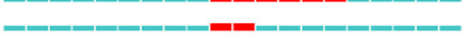 \\
\hline self service & 1997 & 6.7978 & 2008 & 2009 & 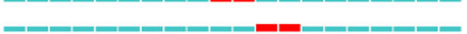 \\
\hline telemedicine & 1997 & 3.4204 & 2010 & 2011 & 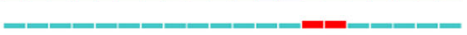 \\
\hline investment & 1997 & 3.0705 & 2010 & 2011 & 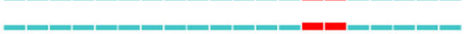 \\
\hline partnership & 1997 & 3.3747 & 2010 & 2011 & 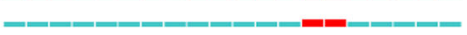 \\
\hline product service system & 1997 & 3.909 & 2012 & 2013 & 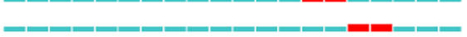 \\
\hline cloud manufacturing & 1997 & 6.0558 & 2014 & 2016 & 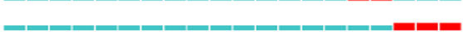 \\
\hline cloud computing & 1997 & 7.6169 & 2014 & 2016 & 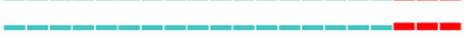 \\
\hline corporate social responsibility & 1997 & 3.4055 & 2014 & 2016 & 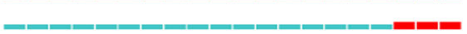 \\
\hline climate change & 1997 & 4.0752 & 2014 & 2016 & 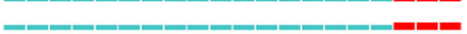 \\
\hline nanomedicine & 1997 & 7.0774 & 2014 & 2016 & \\
\hline sustainable development & 1997 & 3.683 & 2014 & 2016 & 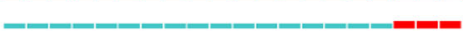 \\
\hline
\end{tabular}

computing," "corporate social responsibility," "telemedicine," "climate change," "sustainable development," and other keywords have sprung up. The above keywords reflect the research hotspots and evolution trends of business model innovation in different periods. Among them, the burst intensity of "Internet" and "e-business" are much higher than other keywords. The impact from these two fields on business model innovation is particularly prominent. Besides, there are six keywords bursting from 2014 till now. These areas reflect the hotspots of business model innovation in the current and even future period of time.

\section{Conclusions}

In order to explore the hotspots and trends of business model innovation for the topic literature over the past 20 years retrieved from SCI and SSCI database, scientometrics with information visualization technology was used to carry on the knowledge mapping with the following indicator: the co-cited references networks, reference bursts, keyword bursts, and keyword co-occurrence networks. The conclusions are as follows.

Firstly, "value creation," "disintegration," "e-commerce," "open source software," "small companies," "performance," "entrepreneurship," "alliance," "strategic innovation," "market orientation," and "capabilities," etc. are the main hotpots. "Business model challenge," "service products architecture," "open innovation," "product innovation," "small business," "renewable energy," "networks," etc. are the new hotpots. Secondly, the trend of hotspots transited from "information technology" at the end of twentieth century, "internet," "e-commerce," "self-service," "mass customization," and "biotechnology" at the beginning of twenty-first century to present "cloud manufacturing," "cloud computer," "corporate social responsibility," "telemedicine," "climate change," and "sustainable development," etc. In addition, the paper [44, 50, 51], etc. plays an important role in the business model innovation research. In recent years, with the emergence of big data, cloud computing, IoT, and other emerging technologies, business model innovation in combination with these trends have been some new hotspots. What will be the hotspot in the next stage? Perhaps the business model innovation of "intelligent robot," "3D printing," or "virtual reality (VR)" is placed in the front of academia and industry. Besides, there is a lack of research on the business mode innovation of networking and IoT. The above research results have shown that research on business mode innovation of networking and IoT is very scarce. Therefore, the research on business model innovation under networking in IoT will be an important hot area in the future.

In order to improve the quality of data, we selected articles and reviews as the research object, which may omit some important research results. Besides, top 100 and top 400 were identified as the analysis indicators, which may not reflect the effect of time factor. In the follow-up study, data sources and data screening criteria will be optimized so as to improve the quality of research continuously. 


\section{Acknowledgements}

We gratefully acknowledge Miss Gaixia Li from the University of Science and Technology Liaoning for polishing the language of the translation,

\section{Funding}

The study is supported by the National Natural Science Foundation of China (grant 71572031) and the National Natural Science Foundation of China (grant 71372121).

\section{Availability of data and materials}

The data were collected from the Web of science database

\section{Authors' contributions}

$Y J$ is the main writer of this paper. He proposed the main idea and carried on data extraction and analysis of the main parts. The parameters used in the paper are determined by SJ. The research on burst words were analyzed by SJ, too. Both authors read and approved the final manuscript.

\section{Competing interests}

The authors declare that they have no competing interests.

\section{Publisher's Note}

Springer Nature remains neutral with regard to jurisdictional claims in published maps and institutional affiliations.

\section{Received: 8 February 2018 Accepted: 18 April 2018 Published online: 02 May 2018}

\section{References}

1. S Zhiyong, L Kui, Y Shiping, O Qingbo, in 2010 IEEE International Conference on Information Theory and Information Security, 17-19 Dec. Design and implementation of the mobile internet of things based on td-scdma network, vol 2010 (2010), pp. 954-957.

2. T Fan, $Y$ Chen, in IEEE International Conference on Network Infrastructure and Digital Content. A scheme of data management in the Internet of Things (2010). pp. 110-114.

3. X Fageda, P Suau-Sanchez, KJ Mason, The evolving low-cost business model: network implications of fare bundling and connecting flights in Europe. Journal of Air Transport Management 42, 289-296 (2015).

4. CV Fanale, BM Demaerschalk, Telestroke network business model strategies. Journal of Stroke \& Cerebrovascular Diseases the Official Journal of National Stroke Association 21(7), 530-534 (2012).

5. Laakkonen, \& Anu, Business model and social network analysis for a nonwood forest product: case:case company and boletus powder. Speculum 40, 545-547 (1965).

6. TF Chen, Developing a New Revenue Business Model in Social Network: A Case Study of Facebook. In Handbook of Research on Demand-Driven Web Services: Theory, Technologies, and Applications, (2014), pp. 197-221. IGI Global.

7. T Zhao, A new business model based on Triple Helix pattern for smart social networking services (The Hong Kong Polytechnic University, Department of Computing, 2017)

8. S Sirikudta, Creative economy strategies affecting business organization success: case study of upper central part industrial entrepreneurs. Eurasip Journal on Wireless Communications \& Networking 2011(1), 1-11 (2011).

9. P Ruckebusch, J Hoebeke, E De Poorter, et al, J Wireless Com Network, 2018, 16 (2018), https://doi.org/10.1186/s13638-018-1024-6

10. T Clauss, Measuring business model innovation: conceptualization, scale development, and proof of performance. R\&D Manag. 47(3), 385-403 (2017)

11. BLR Stojkoska, KV Trivodaliev, A review of Internet of Things for smart home: challenges and solutions. J. Clean. Prod. 140, 1454-1464 (2017).

12. IS Bayram, I Papapanagiotou, A survey on communication technologies and requirements for internet of electric vehicles. Eurasip Journal on Wireless Communications \& Networking 2014(1), 223 (2014).

13. H Breuer, F Lüdeke-Freund, Values-based network and business mode innovation. Int. J. Innov. Manag. 21(03), 1750028 (2017).

14. AG Suherman, TM Simatupang, The network business model of cloud computing for end-to-end supply chain visibility. International Journal of Value Chain Management 8(1), 22-39 (2017).
15. A Aagaard, $P$ Lindgren, The opportunities and challenges of persuasive technology in creating sustainable innovation and business model innovation. Wirel. Pers. Commun. 81(4), 1511-1529 (2015).

16. A Afuah, C L Tucci, E-commerce tutorials and cases: Internet business models and strategies (Tsinghua University Press, Beijing, 2005).

17. A Osterwalder, The Business Model Ontology - A Proposition In A Design Science Approach. University of Lausanne, Lausanne. (2004).

18. P Zeng, T Song, Exploring driving forces for business model innovation: the integrative perspective of internal and external factors. Chinese Journal of Management 11(7), 989-996 (2014).

19. D Mitchell, C Coles, The ultimate competitive advantage of continuing business model innovation. J. Bus. Strateg. 24(5), 15-21 (2003).

20. A Osterwalder, Y Pigneur, CL Tucci, Clarifying business models: origins, present, and future of the concept. Commun. Assoc. Inf. Syst. 16(1), 1 (2005).

21. T Rayna, L Striukova, Adaptivity and Rapid Prototyping: How 3D Printing is Changing Business Model Innovation. In 3D Printing (T.M.C. Asser Press, The Hague, 2016) pp. 167-182

22. C-H Chen, W Yan, K Chen, A supply-chain-oriented business process reengineering strategy for on-demand new product development. Int. J. Comput. Appl. Technol. 32(4), 298-311 (2008).

23. H Zhao, An analysis of mapping knowledge domains of business model innovation. Forum on Science and Technology in China (1), 38-43 (2016). https://doi.org/10.3969/.jissn.1002-6711.2016.01.008

24. XZ Dong, HU Xiao-Feng, SI Guang-Ya, Applying research of information visualization technology in intelligence analysis. Computer Engineering \& Applications 42(34), 175-177 (2006)

25. Chen, C. (2017). Expert review. Science mapping: a systematic review of the literature. Journal of Data and Information Science, 2(2), 1-40.

26. MA Hearst, in Modern Information Retrieval, ed. by R Baeza-Yates, B Ribeiro-Neto. User interfaces and visualization (ACM Press, SETEMBRO, 1999), pp. 257-323.

27. J Kleinberg, Bursty and hierarchical structure in streams. Data Min. Knowl. Disc. 7(4), 373-397 (2003).

28. CM Chen, R Dubin, MC Kim, Orphan drugs and rare diseases: a scientometric review (2000-2014). Expert Opinion on Orphan Drugs 2(7), 709-724 (2014)

29. V Eck, N Jan, L Waltman, Text mining and visualization using VOSviewer. No. arXiv preprint arXiv:1109.2058 (2001). https://arxiv.org/abs/1109.2058

30. NJ Eck, L Waltman, W Glänzel, Citation-based clustering of publications using CitNetExplorer and VOSviewer. Scientometrics 111(2), 1053-1070 (2017).

31. C Chen, How to Use CiteSpace (Lean Publishing, Canada, 2016).

32. CM Chen, R Dubin, MC Kim, Emerging trends and new developments in regenerative medicine: a scientometric update (2000-2014). Expert. Opin. Biol. Ther. 14(9), 1295-1317 (2014).

33. S Svejenova, M Planellas, L Vives, An individual business model in the making: a chef's quest for creative freedom. Long Range Plan. 43(2), 408-430 (2010).

34. BW Wirtz, O Schilke, S Ullrich, Strategic development of business models: implications of the Web 2.0 for creating value on the internet. Long Range Plan. 43(2), 272-290 (2010)

35. P Sanchez, JE Ricart, Business model innovation and sources of value creation in low-income markets. Eur. Manag. Rev. 7(3), 138-154 (2010).

36. X Wu, R Ma, Y Shi, How do latecomer firms capture value from disruptive technologies? A secondary business-model innovation perspective. Engineering Management, IEEE Transactions on 57(1), 51-62 (2010).

37. M Yunus, B Moingeon, L Lehmann-Ortega, Building social business models: lessons from the Grameen experience. Long Range Plan. 43(2), 308-325 (2010).

38. E Karakaya, C Nuur, A Hidalgo, Business model challenge: lessons from a local solar company. Renew. Energy 85, 1026-1035 (2016).

39. R Bohnsack, J Pinkse, A Kolk, Business models for sustainable technologies: exploring business model evolution in the case of electric vehicles. Res. Policy 43(2), 284-300 (2014).

40. TB Christensen, P Wells, L Cipcigan, Can innovative business models overcome resistance to electric vehicles? Better place and battery electric cars in Denmark. Energy Policy 48, 498-505 (2012).

41. M Ernkvist, The double knot of technology and business-model innovation in the era of ferment of digital exchanges: the case of OM, a pioneer in electronic options exchanges. Technol. Forecast. Soc. Chang. 99, 285-299 (2015).

42. RR Hermann, J Köhler, A Scheepens, Innovation in product and services in the shipping retrofit industry: a case study of ballast water treatment systems. J. Clean. Prod. 106, 443-454 (2015). 
43. C Chen, CiteSpace II: detecting and visualizing emerging trends and transient patterns in scientific literature. J. Am. Soc. Inf. Sci. Technol. 57(3), 359-377 (2006).

44. R Amit, Z Christoph, Value creation in e-business. Strateg. Manag. J. 22, 493-520 (2001).

45. HW Chesbrough, RS Rosenbloom, The role of the business model in capturing value from innovation: evidence from Xerox Corporation's technology spin-off companies. Industrial \& Corporate Change 11(3), 529-555 (2002).

46. V Mangematin, S Lemarié, J-P Boissin, D Catherine, F Corolleur, R Coronini, et al., Development of SMEs and heterogeneity of trajectories: the case of biotechnology in France. Res. Policy 32(4), 621-638 (2003).

47. J Magretta, Why business models matter. Harv. Bus. Rev. 80(5), 86-92 (2002) 133.

48. HW Chesbrough, Open Business Models: How to Thrive in the New Innovation Landscape (Harvard Business School Press, Boston, 2006).

49. M Morris, M Schindehutte, J Allen, The entrepreneur's business model: toward a unified perspective. J. Bus. Res. 58(6), 726-735 (2005).

50. HW Chesbrough, Business model innovation: opportunities and barriers. Long Range Plan. 43(2), 354-363 (2010)

51. DJ Teece, Business models, business strategy and innovation. Long Range Plan. 43(2), 172-194 (2010).

52. NJV Eck, L Waltman, Visualizing Bibliometric Networks (Springer International Publishing, 2014).

53. Q Chang, D Wang, XU Lili, L Zhang, Study of hotspots evalution and frontier trends of regional innovation theory in China-based on knowledge mapping domain. Science \& Technology Management Research 109(18), 81-86 (2016)

54. H Chesbrough, W Vanhaverbeke, J West, Open Innovation: Researching a New Paradigm (Oxford University Press, Oxford, 2006).

55. S Hotho, KChampion, Small businesses in the new creative industries: innovation as a people management challenge. Manag. Decis. 49(1), 29-54 (2011).

56. KH Huarng, Entrepreneurship, process innovation and value creation by a non-profit SME. Manag. Decis. 49(2), 284-296 (2011).

\section{Submit your manuscript to a SpringerOpen ${ }^{\circ}$ journal and benefit from:}

- Convenient online submission

- Rigorous peer review

- Open access: articles freely available online

- High visibility within the field

- Retaining the copyright to your article

Submit your next manuscript at $\gg$ springeropen.com 